\title{
A CIDADE POROSA DE BRUNO CARVALHO
}

\author{
Mateus Sanches Duarte ${ }^{T}$
}

\begin{abstract}
RESUMO: Este texto é uma resenha do livro Cidade porosa: dois séculos de história cultural do Rio de Janeiro, de Bruno Carvalho, vertido ao português em 2019 pela editora Objetiva. A resenha se propõe a apresentar como o autor utiliza o conceito de "porosidade" para reconstruir a história cultural do Rio de Janeiro a partir da experiência cultural da Cidade Nova, bairro que foi devastado para a construção da Avenida Presidente Vargas na década de 1940.
\end{abstract}

PALAVRAS-CHAVE: Cidade porosa. História Cultural. Rio de Janeiro. Cidade Nova.

\section{THE POROUS CITY OF BRUNO CARVALHO}

\begin{abstract}
This text is a review of the book Porous City: A Cultural History of Rio de Janeiro, by Bruno Carvalho, published in 2019 by Objetiva. The main objective of the review is to present how the author uses the concept of "porosity" when reconstructing the cultural history of Rio de Janeiro from the cultural experience of Cidade Nova, a neighborhood that was devastated for the construction of Avenida Presidente Vargas in 1940.
\end{abstract}

KEYWORDS: Porous city. Cultural History. Rio de Janeiro. Cidade Nova.

\section{LA CIUDAD POROSA DE BRUNO CARVALHO}

\footnotetext{
${ }^{1}$ Mestrando pelo Programa de Pós-graduação em Comunicação e Cultura da Universidade Federal do Rio Janeiro. E-mail: mateus.sanches14@gmail.com. Orcid: https:/ / orcid.org/00000002-0416-8818.
} 
RESUMEN: Este texto consiste en una reseña del libro Cidade porosa: dois séculos de história cultural do Rio de Janeiro, de Bruno Carvalho, publicado en 2019 por la editorial Objetiva. El texto propone presentar como el autor utiliza el concepto de "porosidade" al reconstruir la historia cultural de Río de Janeiro a partir de la experiencia cultural de Cidade Nova, un barrio que fue devastado por la construcción de la Avenida Presidente Vargas en los años de 1940.

PALABRAS CLAVE: Ciudad porosa. Historia Cultural. Rio de Janeiro. Cidade Nova.

O livro Cidade Porosa: dois séculos de bistória cultural do Rio de Janeiro (2019), de Bruno Carvalho, é uma tradução e adaptação de Porous City: A Cultural History of Rio de Janeiro, lançado em 2013 pela Liverpool University Press. O livro utiliza o conceito de "porosidade" para pensar as transformações urbanas e sociais da Cidade Nova, um bairro criado no Rio de Janeiro por um decreto real em 1811, e desmantelado para a construção da Avenida Presidente Vargas em 1944. Motivado pela pergunta "como uma cultura e uma autoimagem definidas pela mistura coexistem com uma disparidade socioeconômica tão gritante?" (CARVALHO, 2019, p. 40), o autor encontra na Cidade Nova uma versão exemplar dessa contradição carioca.

O marco para análise de Carvalho é o ano de 1811, quando Dom João VI estabeleceu um decreto real incentivando a construção de casas de mais de um andar, especialmente casas maiores, como os sobrados que anos depois virariam os cortiços -, em terrenos pantanosos do que então se chamava de Cidade Nova. Com o aterramento para melhoria da habitação nesta região, houve um crescimento populacional considerável na área. Além de ser um espaço de encontro para o desenvolvimento do Rio de Janeiro, a região também era um lugar muito conveniente para família real, cujos integrantes moravam em São Cristóvão, na Quinta da Boa Vista. Em pouco tempo a Cidade Nova começou a ser ocupada por múltiplas etnias africanas, judeus asquenazes, ciganos, além de imigrantes das áreas rurais brasileiras e da Europa, ficando conhecida como "Pequena África" e "Bairro Judeu".

Carvalho mostra que alguns observadores estrangeiros perceberam - e cada vez mais a população local também começou a notar - que existia 
uma divisão muito clara entre a Cidade Nova e Cidade Velha, tendo o Campo de Santana como marco fronteiriço entre as "duas cidades". O lugar sede do Quartel General do Exército e do Senado também era lugar de encontro das festas de santos, umbigadas e batuques. Os pântanos da Cidade Nova e a urbanizada Cidade Velha revelavam, de certo modo, uma fronteira entre o Brasil rural, imperativo de um desordenamento social, e o Brasil urbano, visto como racional e civilizado. Enquanto as camadas mais aquilatadas da sociedade começaram a ocupar outras áreas da cidade, como os subúrbios da Zona Sul, a Cidade Nova foi se adensando e se transformando em um ponto de encontro intenso entre povos e culturas diferentes.

A utilização do conceito de "porosidade" para Bruno Carvalho analisar o contexto urbano é influenciado por um famoso artigo de Walter Benjamin e Asja Lacis sobre Nápoles, publicado no Frankfurter Zeitung, em 1925. Nele, os autores atribuem à porosidade essa característica de interpenetração de atividades de diversos atores sociais em um cenário de "imprevisíveis constelações de acontecimentos" (BENJAMIN, 2017, p. 11). Para Carvalho (2019, p. 63), as formulações de Benjamin e Lacis encontram ressonância em descrições do Rio de Janeiro: "irresistíveis, os dias de festas impregnam todos os dias de trabalho. A porosidade é a lei inesgotável da vida desta cidade". Interessado nas trocas e nos encontros que ajudaram a criar a cultura do samba e do carnaval, o autor mostra como a porosidade de diversas pessoas, atores e povos também possibilita analisar o encontro como um instrumento de subversão. $O$ ponto de reunião dos primeiros blocos de carnaval embalados pelo samba, por exemplo, era a Praça Onze, uma vibrante praça pública que rendeu muitos artigos apáticos nos periódicos que não imaginavam que o samba e o carnaval seriam transformados em símbolos decisivos do projeto nacional durante a Era Vargas.

Entre a cartografia letrada e a geografia cultural, o autor de Cidade porosa busca nos romances do século XIX as representações possíveis da Cidade Nova. No clássico de Manuel Antônio de Almeida, Memórias de um Sargento de Milícias (1853), Carvalho sinaliza como o romancista expressa uma perspectiva sobre o bairro diretamente associada à marginalidade 
urbana, visão condizente com os discursos da imprensa na época e da ficção da cidade letrada sobre esta região periférica. Em Memórias..., a Cidade Nova está associada ao perigo, à sujeira, à imundice e à feiura que não carece de um ar de mistérios. Ainda assim, Manuel Antônio é um dos poucos romancistas do século XIX que se dispôs percorrer diversos espaços sociais do Rio de Janeiro em suas narrativas. Outro romancista estudado por Carvalho é Machado de Assis, que frequentemente criava de personagens que passeavam por lugares da cidade em que os seus leitores de então jamais cogitaram pisar. Nos contos "Um erradio" e "Uns braços" Machado esboça, no argumento de Carvalho, um pensamento crítico sobre a cidade letrada, a partir de um viés autorreflexivo sobre os ímpetos da modernização em curso na cidade, que era tão evidente na Cidade Nova.

Após a consolidação do Estado Novo, entre os anos de 1930 e 1940, a Cidade Nova foi desmantelada para a construção da Avenida Presidente Vargas, com a demolição de prédios e áreas centrais, e dando fim a uma importante região cultural do Rio de Janeiro. Para analisar essa cena histórica e refletir sobre o "apagamento" de um cenário urbano, Carvalho recorre ao conceito de "palimpsesto", um "pergaminho cujo texto primitivo foi raspado para receber novo texto" (LUFT, 2009, p.498). $\mathrm{Na}$ utilização que faz o autor, palimpsesto é uma categoria interessante para pensarmos nas "raspagens" da superfície visível que deixam marcas e camadas históricas. Escovando a história a contrapelo, como defendia Walter Benjamin (1985) em sua tese VII "Sobre o Conceito de História", Carvalho afirma algo que tomamos consciência no desenrolar dos seus argumentos:

Como resultado, temos uma melhor compreensão de como a demolição de quase seiscentas construções, no que ficou conhecido como bota-abaixo, levou a uma degradação das condições de vida de um grande número de pessoas e permanece profundamente interconectado com o crescimento das favelas. Hoje, entendemos mais claramente como a elite brasileira igualava a noção de civilização ao que vinha da França: e, como Needell coloca, 
de como "civilizar" significava deixar para trás certas práticas populares consideradas anacrônicas, perseguindoas e reprimindo-as, em particular as de origem africana ou relacionadas a grupos de imigrantes, especialmente na esfera pública (CARVALHO, 2019, p. 125).

Cidade porosa, livro organizado em 6 capítulos, aposta nas imagens que a literatura, a poesia, a música e o cinema oferecem para reconstruir esse contexto cultural que foi "raspado". Perseguindo as contradições da cultura, Carvalho aponta como o samba, inicialmente visto como algo desprovido de valor cultural pelas elites, rapidamente ascende aos estigmas, sendo reconhecido como parte constitutivo da identidade cultural do Brasil pela geração dos modernistas, ao mesmo tempo que a Praça Onze, considerada o "berço do samba", foi removida da "paisagem do Rio de Janeiro pelo mesmo governo que usou a música como instrumento de unificação nacional" (CARVALHO, 2019, p. 252). Tendo seus moradores afastados para outros cantos muito mais distantes do centro, a Cidade Nova acabou virando uma referência mártir importante para escritores, artistas, e até mesmo para visitantes estrangeiros, como Orson Welles, que efetuaram um papel decisivo em parte das narrativas construídas sobre o Brasil do século XX, como "o país do carnaval" e da "democracia racial".

Resgatando alguns atores fundamentais deste novo contexto cultural do Rio de Janeiro, Carvalho nos lembra de Tia Ciata, Manuel Pedro dos Santos e dos Oito Batutas, além de recuperar uma entrevista de Pixinguinha, realizada em momento no qual o carnaval já entrava na agenda de festas da cidade:

Entrevistado anos depois, Pixinguinha não diminui o significado, no contexto de uma sociedade racista, do convite para tocar no chique Palais, na avenida Rio Branco com a Sete de Setembro, no coração do Centro da cidade: "Fiquei surpreso, pois convites desse tipo só costumavam ser feitos a músicos brancos" (CARVALHO, 2019, p. 171). 
O autor demonstra ainda como as reformas urbanas em curso durante o processo de modernização do Rio de Janeiro nas primeiras décadas do século XX tinham preocupações com a imagem do Brasil no exterior. A cidade do Rio de Janeiro, como vitrine do Brasil, necessitava criar uma imagem competitiva o suficiente com as demais cidades latinoamericanas. Segundo Carvalho (2019), na visão dos governantes, nem a Cidade Nova nem os morros ao redor contribuíram muito para se construir uma imagem mais atrativa da cidade. Neste contexto, se as autoridades locais e a imprensa tratavam os moradores das margens da cidade como seres primitivos, atrasados e insalubres, alguns artistas e escritores se propuseram a construir novas imagens da região e de seus moradores, associando-os a ideia de um "Brasil autêntico". Oswald de Andrade, por exemplo, considerava a favela como um símbolo esteticamente nacional do país, como é expresso em seu "Manifesto Da Poesia Pau-Brasil", onde lemos: "a poesia existe nos fatos. Os casebres de açafrão e de ocre nos verdes da favela, sob o azul cabralino, são fatos estéticos" (ANDRADE, 1972, p. 5).

O processo de desfiguração da Cidade Nova, no argumento mais decisivo de Bruno Carvalho, não deve ser entendido apenas como um impulso modernizador, de melhorar a condição de circulação dos automóveis, ou mesmo em virtude da especulação imobiliária. Para ele, a questão ideológica tem um papel histórico substancial neste processo. Pois, apesar da Cidade Nova ter sido um local central na história cultural local e nacional, optou-se por seu apagamento e esquecimento. Foi apenas em 1984, com a construção do Sambódromo, durante o primeiro mandato do governador Leonel Brizola, que as escolas de samba saíram das ruas, tendo o espetáculo do carnaval um equipamento permanente na cidade. Ainda que essa institucionalização tenha sido vista de maneira crítica, como se o Sambódromo transformasse a experiência subversiva de uma festa popular de rua em um mero produto da indústria cultural, estas manifestações culturais e populares não deixaram de existir nas ruas. Histórias de um passado inacabado, a Cidade Nova se tornou um caso paradigmático sobre a "cidade porosa", pois ainda que a cultura marginalizada da Praça Onze 
tenha ocupado um lugar importante nas cartografias letradas da cidade, nem sempre essa porosidade foi bem-vinda ou desejável.

A porosidade não deve, porém, ser entendida como uma qualidade, mas sim como uma categoria que valoriza o caráter espacial, relacionando-o às camadas temporais do Rio de Janeiro. O livro é uma contribuição teórica e metodológica relevante sobre as relações entre cultura e processos de urbanização, na medida em que compreende que uma "cidade partida" - como a apontada por Zuenir Ventura (1994) em seu livro homônimo - é capaz de coexistir com as implicações de misturas e encontros, assim como a "cidade porosa" pode coexistir com processos de modernização que aprofundam a segregação espacial, social e racial. Nessa relação viceversa, o Brasil do século XX é a prova precisa dessa coexistência: ao mesmo tempo em que se constrói culturalmente a valorização do encontro dos diferentes, os processos de urbanização e modernização propõem segregações e apagamentos.

No Rio de Janeiro do século XXI, no qual grandes edifícios e condomínios residenciais se fecham em grades, portões e muros de contenção, o projeto da cidade dos carros e dos Shopping Centers encontra uma versão bem-acabada na Zona Oeste, principalmente na Barra da Tijuca. Com políticas de segurança pública malsucedidas, como as Unidade de Polícia Pacificadora (UPP's), a "cidade partida” parece querer distância da "cidade porosa", principalmente da população jovem e negra das favelas e periferias. Esta cidade-vitrine se preparou para receber dois dos maiores megaeventos do mundo, a Copa do Mundo Fifa em 2014 e os Jogos Olímpicos em 2016, que contaram com diversas obras pela cidade. O legado dos megaeventos foi o de violação de direitos humanos, com a remoção de centenas de famílias em processos no mínimo questionáveis, e a construção de verdadeiros "elefantes brancos".

A partir das variadas imagens criadas sobre a Cidade Nova ao longo de dois séculos, o livro de Bruno Carvalho abre caminhos para contrastálas com o contexto contemporâneo, não só por revelar os desejos inscritos em certos contextos, mas por reforçar que a história se escreve no presente. Nesta importante contribuição, que dialoga com o pensamento social produzido no Brasil, o conceito de "porosidade" pode abrir caminhos 
interessantes, por exemplo, para estudar como as universidades públicas, historicamente tão elitizadas, vem se apresentando como este lugar de encontros entre diferentes públicos e culturas, haja visto a inserção de outras camadas sociais em suas cadeiras, corredores e bibliotecas durante a última década. Questões como esta são, por excelência, questões urbanas, e nos levam a questionar: o que fazer com as ambivalências da cidade partida, porosa e maravilhosa que se apresenta sobre o Rio de Janeiro? Uma pergunta difícil, que nos conduz a mais perguntas do que respostas acabadas; mesmo porque, como Bruno Carvalho afirma em sua conclusão, "seu passado, independentemente de para onde tenha ido ou possa ir, continua a dialogar com as histórias culturais brasileiras e com as diversas maneiras de se estar no mundo, um mundo urbano." (CARVALHO, 2019, p. 297).

\section{REFERÊNCIAS}

ANDRADE, Oswald de. Do Pau-Brasil à antropofagia e às utopias: manifestos, teses de concursos e ensaios. Rio de Janeiro: Civilização brasileira, 1972.

BENJAMIN, Walter. Imagens de pensamento/ Sobre o haxixe e outras drogas. Belo Horizonte: Autêntica Editora, 2017.

BENJAMIN, Walter. Magia e técnica, arte e política: ensaios sobre literatura e bistória da cultura. São Paulo: Brasiliense, 1985.

CARVALHO, Bruno. Cidade porosa: dois séculos de bistória cultural do Rio de Janeiro. São Paulo: Objetiva, 2019.

VENTURA, Zuenir. Cidade partida. São Paulo: Companhia das Letras, 1994.

Texto recebido em 17/09/2020 e aprovado em 13/11/2020 